\title{
Analysis of Alienation in Informal Education: Media Skepticism and Spiral of Silence in the Network Society
}

\author{
Osman Yilmaz Kartal ${ }^{1}$ \\ ${ }^{1}$ School of Education, Çanakkale Onsekiz Mart University, Çanakkale, Turkey. \\ Correspondence: Osman Yılmaz Kartal, School of Education, Çanakkale Onsekiz Mart University, Çanakkale, \\ Turkey.
}

Received: July 16, 2018

Accepted: August 2, 2018

Online Published: August 3, 2018

doi:10.5430/ijhe.v7n4p110

URL: https://doi.org/10.5430/ijhe.v7n4p110

\begin{abstract}
In the study, the alienation in the network society is investigated. Facebook, which is highly effective among network community applications, has been examined as an informal learning tool. In this context, the topic of learning is "political, social, religious, cultural contents that society is sensitive". The research was conducted with the participation of university students who are members of the network society. Spiral of silence (SoS) was taken into account as a sign of alienation. It has been examined whether the media skepticism is effective in solving the problem of alienation. In this context, the relationship between spiral of silence and media skepticism has been investigated. As a result of the research, it was understood that young adults who are university students are in the spiral of silence in sharing about "political, social, religious, cultural contents, society is sensitive" and therefore alienation exists. In the context of media skepticism, participants' skepticism to others' posts is high, skepticism to self posts is low. While there is a significant, negative and low level of correlation between spiral of silence and skepticism to others posts, there is no significant relationship between spiral of silence and skepticism to self posts. There is a potential for skepticism to others' posts to be effective in resolving alienation in network society.
\end{abstract}

Keywords: alienation, facebook, informal learning, media skepticism, network society, spiral of silence

\section{Introduction}

With its formal, nonformal and informal processes, education aims to make the individual actualize himself/herself. The level of realization of this goal mediates the actualization of the society itself. The most basic goal of the education process is to synthesize the social culture itself by acting from the individual difference of the constituents of the society. Through dialectical methods and intellectual capital, individual differences are in a continuous motion, and this movement becomes a source of active change. This change leads to a dynamic characterization of society and culture, and makes synthesis of society and culture the result of change. In this functioning of the system, the members who constitute the society need to take an active role in the social processes and become a source of change. In the process of socialization, this role that individuals should possess is defined as "active citizenship" and active citizenship is gained to individuals through education. However, when the realities of society and education are taken into consideration in the $2010 \mathrm{~s}$, it can be seen that the stated standards can not be transferred to life. In formal education, alienated learners can not bring functionality to their socialization processes. When the aforementioned community synthesis process is examined, it is seen that there is a new society type called network society with the reason of the development of information technologies. This new living space, which creates informal educational opportunities as an alternative to formal educational opportunities, has caused differentiation in individual behavior codes. Learning becomes practical and individuals assume responsibility for learning. This brings with it opportunities and limitations. While the autonomous individual in the network society exhibits a more participatory character, he/she exhibits different characteristics in behavioral codes similar to alienation in formal education. Individuals create different identities in their network society beyond their own identities. Moreover, in order not to be contrary to authority and the others, they become silent in the network society where freedom of thought is most active. This is interpreted as the existence of alienation in formal education as well as in the network society, which is regarded as informal education environment. There are different suggestions for the solution of alienation, which has become an educational problem. One of the suggested variables to consider for alienation is media skepticism. In this study, the level of alienation of the individuals in the network society is determined by the perspective of Spiral of Silence (SoS); the relationship between alienation in the network society and media skepticism is investigated. 


\subsection{Facebook as Informal Education / Learning Opportunity}

Initiatives that are mediated by the socialization process of the individual are carried out through 3 different types of education / learning called formal, non-formal and informal education / learning (Colardyn and Bjornavold, 2004; Eshach, 2007; La Belle, 1982). Informal education / learning out of the stated types of education / learning is separated by sharp lines from others. Informal education is defined as the most natural learning approach. The structuring, production, transfer and functionalization of information are carried out entirely through daily routines (spontaneous communication, interaction, talking, etc.) (Pettenati and Ranieri, 2006). Laurillard's (2009) definition of informal learning, "there is no teacher, no defined curriculum topic or concept, and no external assessment. The informal learner selects their own 'teacher', who may be a peer, or may not be a person; they define their own 'curriculum', as what they are interested in learning about; and they choose whether to submit to 'assessment' by others. (p. 12)". There is an unplanned, flexible, certificate-based learning and learning environment.

The use of technology in educational processes offers more opportunity to acquire and use learning autonomy than traditional education practices (Åkerlind and Trevitt, 1999). Thus, in the learning environment where autonomous learning is included, the nature of the learning and the educational process are undergoing serious changes. One of the most basic indicators of this change is that the nature of learning in the network society differs significantly from other learning environments. The researches (Albors, Ramos and Hervas, 2008; Bessenyei, 2008; Chan, Hue, Chou and Tzeng, 2001; Chang, Cheng, Deng and Chan, 2007; Chris, 2004; Haythornthwaite and Laat, 2010; Nasr and Ouf, 2011; Warschauer, 2007) that investigate the learning nature of the network society and the change in the nature of this learning draws attention. In the educational researches, how, what, who, when, where and why we learn questions are highlighted (Chan, Hue, Chou and Tzeng, 2001; Warschauer, 2007) and new learning models (the future-classroom, the community-based, the structural knowledge, and the complex-problem learning models) are discussed (Chan, Hue, Chou and Tzeng, 2001). Online learning societies are being tried to be defined and explained (Chang, Cheng, Deng and Chan, 2007). According to Snyder (2001), technological evolution is deeply influencing educational approaches. Similarly, Krumsvik (2009) notes that digital trends have a decisive influence on schools, pedagogy and subjects.

Network society has given a new paradigm to society and socialization approaches, has changed the reality of public sphere and deeply influenced communication culture (Castells, 2000; Castells, 2004; Castells, 2010; van Dijk, 2006). This society, therefore, has mediated the transition from universal reality to a multiversal reality, creating its own universes and new universal realities. In the multiversal reality, the network society constitutes the new universe, and a large part of the learning activities take place in this new phase.

Through this network of human social behavior and technology unified, the informal e-learning approach has taken its place among educational applications (Pettenati and Ranieri, 2006). In addition, there are efforts to develop educational models that take into account e-learning opportunities such as blended learning (Bull, Thompson, Searson, Garofalo, Park, Young and Lee, 2008; Lai, Khaddage and Knezek, 2013). For example, in Erjavec (2013)'s study, he emphasizes that Facebook is seen as an informal learning tool with complementary and supplemental qualities for in-class learning. When these and similar initiatives are considered, social media-based informal learning is a powerful learning opportunity whether it is judged as hegonomic (dominant according to formal learning) or democratic (equivalent to formal learning). Therefore, in order to understand the nature of the learning and to make the learning process functional, it is necessary to consider the network society which is regarded as a learning opportunity.

We can evaluate the functionality of the network society with the useful or harmful implications of social media. When the researches conducted are examined, it can be seen that the social media is beneficial amongst the benefits of strengthening social capital, supporting self-esteem and life satisfaction positively (Ellison, Steinfield, Lampe, 2007), supporting the learning process (Hew, 2011; Mix, 2010), mediating formative assessment and evaluation, creating an alternative performance environment, acquiring private sphere knowledge, promoting and accelerating learning (Chen and Bryer, 2012), presenting socialization and communication richness, and enhanced learning opportunities (O'Keeffe and Clarke-Pearson, 2011). These are considered as opportunities to support the individual's cognitive, affective and social development. These benefits can be further increased. However, there are also negative effects of social media. These negative effects are exemplified as creating grounds for sexting and cyberbullying, creating privacy violations, creating internet addiction, causing problems that affect physical and mental health such as depression and concurrent sleep deprivation (O'Keeffe and Clarke-Pearson, 2011), adversely affecting academic performance, decreasing literacy standards and creating threats to social values (Erjavec, 2013). According to Erjavec (2013), among all these positive and negative effects, the most remarkable is the positive effect 
on cognitive development. Social media networks are an effective learning platform that supports the information production processes of individuals and is based on social constructivism and co-constructivism approaches. Social media is also developing participants' self-determination skills by providing the opportunity to identify learning objectives and self-direction skills by providing the opportunity to organize learning processes. Participatory and collaborative nature of learning is also often observed (Greenhow and Lewin, 2016). However, it is necessary to pay attention to a basic principle for the functioning of this cognitive developmental environment: Greenfield (2009) emphasizes that informal education for the development of cognitive skills in the networked society should be done through a media diet. It is recommended to use only the healthy, harmless, supportive and powerful aspects of technology.

A good teaching is to teach students how to learn, how to think, how to be motivated and how to remember them, as well as teaching them what to teach (Weinstein and Mayer, 1983). These criteria must be taken into account in teaching practice. Facebook is one of the social networks that provide meaningful opportunities in this regard. When the literature is examined, there are studies evaluating Facebook as an informal learning environment (Erjavec, 2013; Madge, Meek, Wellens and Hooley, 2009; Vivian, 2011). When Facebook is viewed as an informal learning tool, it is a platform for learners to gain experience and achievements in their learning activities. Vivan (2011) notes that university students see Facebook as an effective informal learning tool. Learners have access to contemporary issues and experts' approaches to these issues more practically on Facebook than schools that are formal education institutions. Facebook enriches learning processes by enabling learners to interact with real-world problems (Cain and Policastri, 2011). Madge, Meek, Wellens and Hooley (2008) define Facebook as "social glue". As a social glue, Facebook is becoming a platform for "co-operation and solidarity" for learners to overcome their learning difficulties.

\subsection{Alienation in Education and Networking Society}

Alienation in the school environment is explained by negative student behaviors. Examples of these negative behaviors are self-isolation, failure, absenteeism, and dropping out. Alienation is also interpreted as the absence or break of the learner's connection/bond with other students, teachers and school communities (ie school stakeholders) (Mau, 1992). In formal education, three sources of alienation attract attention. Dean (1961) refers to these as social isolation, powerlessness, and normlessness. Social isolation is unable to achieve meaningful and healthy relationships with other members of the group and loneliness in the group in which the individual / student is a member. Powerlessness refers to the inability of individuals / learners to influence decisions or choices of others. It is also interpreted as an abandonment of the individual / student because of "resistance and persistence of the others" or "weakness and failure of himself". Others have a controlling power over the individual / student. Normlessness is defined as the inability of a student to comply with school rules, principles and values. The student opposes and rejects the norms of the school. The individual / student's own norms are in opposition to the dominant norms accepted by others (Dean, 1961).

Alienation in formal education is also seen in the network society. Kryshtaleva (2016) states that alienation in the digital world (network society), defined as modern alienation, has micro and macro level effects. The individual is faced with the problem of alienation both to himself/herself and to his/her surroundings. The visual desires of the digital world, defined as visual violence, cause the individual to move away from his / her reality, preferring reality presented on the screen. Regardless of whether it is traditional or digital media, individuals continue their process of alienation in the media. Individuals are distracted from the meaning and importance of media content, do not read critically, and as a result, they accept the reality of the media as real (Ringer and Briziarelli, 2016). This is an indication that the media continues to have constructive role on both individuals' realities and identities, and that it is a source of alienation.

Kellner (2006) describes the source of alienation as human condition. There will always be a problem of alienation with the cause of the complexity and conflict nature of human life. Because of the separations and differences between human beings, nature, cultures and technologies, consensus becomes impossible. In this case, technology is effective on people and constantly transforming people. Web2.0 technology, defined by Andrejevic (2014) as digital shadow, is a decisive power in digital era, from mobility to personal preferences. As new technologies are developed, new forms of alienation emerge (Kellner, 2006).

When social media platforms are investigated, it appears that alienation continues to actively exist. By concealing individual identities, the use of anonymous nicknames, the density of meaningless and unnecessary discussions, and the low functionality of the language used confirm the existence of a new area of alienation. In addition, alienation of communication is seen as one of the main problems. Because communication is one of the most fundamental 
components of perception, interaction and association processes and is the most important feature of the social relations of the network society (Leshchenko, Sokolova and Teplova, 2016). Therefore, the alienation of communication is one of the problems to be solved in the network society, which is considered in terms of the informal education / learning environment.

Communication is seen as the only way to reproduce society (Leshchenko, Sokolova and Teplova, 2016). Therefore, it also plays an important role in the construct of a society. Communication is the mainstay of the existence of the network society. In addition, communication provides dialectic. The need for the other's opinions (antithesis) in the process of constructing the individual's reality is the condition for functional synthesis. But when there is alienation in the network society, the dialectic process can not be functionalized. Because the individual refrains from fulfilling his / her responsibility to produce / develop thesis or antithesis.

Information and communication technologies are also among the solutions of alienation as much as the reason of alienation (Kellner, 2006). The quality of intellectual equipment that individuals possess is determinative of their role in the network society they are involved in. Individuals with strong intellectual equipment can reduce the problem of alienation to the minimum level in network society. Ringer and Briziarelli (2016) state that social interaction in social media can prevent alienation. This can be achieved through hyper-connectivity, sociability and transparence.

\subsection{Alienation and Spiral of Silence (SoS)}

According to Noelle-Neumann (1974, 1977, 1991), Spiral of Silence (SoS) includes the threat of exclusion, fear of exclusion, evaluation of the opinion climate, disclosure or concealment of opinions. The sources of fears of exclusion and social isolation of individuals are variables of popularity, esteem and respect. The individual exhibits the behavior of adopting and adhering to the massive ideas accepted as the dominant with the fears of social isolation and exclusion. This situation causes the thought of the individual to depend on the thought of others. The individual, who has a different view from the others, gives up expressing his/her ideas. Thus, a spiral of silence occurs in the process. This leads to the continuation of the existence of authority-based thoughts.

Fear of social isolation brings silence (Hayes, Matthes, \& Eveland, 2011). Individuals tend to express opinions that are similar to the accepted ideas of a majority, and refrain from expressing ideas that are incompatible with the acceptance of the majority. This situation emphasizes the concept of climate of opinion. The impact of the climate of opinion on internet shares is being investigated (Miyata, Yamamoto and Ogawa, 2015). For example, in Miyata, Yamamoto and Ogawa (2015) research, Twitter is accelerating spiral of silence. And Twitter shares are shaped by the majority opinion.

A network society, in which the ideas of majority are flowed and ideas are homogenized, will not be realistic in the realization of cultural synthesis. Because the world, which has become a small village (McLuhan and Powers, 1989), is expected to exhibit a heterogeneous structures of ideas when considering the potential of individual differences in its populations. Otherwise, a culture of standardization is spreading, and both the individual and society are becoming alienated from themselves. The existence of Spiral of Silence further increases alienation.

Social media is anti-authoritarian and anti-centralist and offers its users the freedom to create a "spiral of dialog". However, users create micro spiral of silence in the "spiral of dialog". More than one group formed on social media creates more than one climate of opinion. Involvement in the climates of opinion is due to the spiral of dialog. In this case, the individual analyzes and evaluates the characteristics of each different climate of opinion. The most unfavorable situation that follows is that the individual abandons the spiral of dialogue and is involved in the spiral of silence. On the other hand, individuals are following or interacting with people with similar climate of opinion characteristics in their social media accounts. This causes the spiral of silence to be naturally demanded or created. Thus, there are groups that are fed from the same intellectual sources as representatives of the same authority. This problem, which is encountered in formal education environments, is also observed on social media, which is considered as an informal education environment. Social media should offer a climate of opinion in which different ideas live, no social isolation and exclusion threats, and individuals can freely express their own ideas. Thus, the individual will not face the alienation problem both to himself/herself and his/her environment.

The character of the climate of opinion is the determinant of the willingness of individuals to engage in dialogue. A friendly opinion climate is more effective than a hostile opinion climate (Hayes, 2007). Gearhart and Zhang (2015) point out that spiral of silence exists in social network sites such as Facebook. Research carried out in this context is remarkable. Hoffman and Lutz (2017) found that fear of isolation has reduced the willingness of individuals (Young Facebook users under age of 30) to speak on controversial political issues over Facebook. In case the opinion climate reflects the hostile environment rather than the compromise, the individuals apply self-censorship in case of 
declaring their political views. The dominant idea is causing the silence of others. However, in the absence of fear of isolation and communication apprehension, political interest and the use of active Facebook increase the dialogical willingness and hinder silence. For example, in the Fox and Warber (2015) research, it was observed that LGBT + individuals who hide their identities on Facebook have entered the spiral of silence and become silent in the face of the majority's ideas. On the contrary, the individuals who explain their LGBT+ identities on Facebook are not entering the spiral of silence. Thus, the voices of the minority silence the voices of the majority. This is an indication that the individual has to resolve the self-alienation process in order to get out of the spiral of silence. Expressing your own identity and individual difference is effective in destroying the fear of isolation.

In Wu (2017)'s research, it is understood that the "the participants' contextual fear of isolation, perceived online anonymity, opinion congruity with other commenters, and issue involvement" are decisive on participants to share/post their own ideas/views in online news discussions. In the Facebook groups formed by close friends, the climate of opinion is positive and the spiral of silence is weakening (Chen, 2011).

In social network sites defined as Informal learning environment, alienation and silence coexist together. Individuals' culture and environment in the network society, identity and status in the network society, nature of the communication in the network society can be determinants of alienation.

\subsection{Media Skepticism as Solution of Alienation Problem}

Media skepticism is the determinant of acceptance or rejection of the climate of opinion (Tsfati, 2003). Tsfati (2003, 78) gives an insight into the effect of skepticism: "Not all skeptics rejected the media's climate of opinion and not all non-skeptics accepted it.". Therefore, the media skepticism can not provide a "pure" solution to the climate of opinion quality problem. However, it has the potential to reduce the level of acceptance of non-hygienic, dirty information (information that has been manipulated or disinformed). Media skepticism is defined as skepticism about media messages, as assuming that the media does not provide reliable information, that it provides dirty information within the framework of power acquisition and commercial purposes (Tsfati and Cappella, 2003). According to this definition, media skepticism is a suspicion of every media source that generates and transmits media messages. In this context, media skepticism requires the individual to doubt the content of professional media producers in traditional media, as well as the media content shared by each individual who has the opportunity and freedom to produce media in the new media. This requires the individual to be suspicious of his or her own media messages, as well as to suspect the content of others who professionally or authentically produce the media. Tsfati (2003) states that the media is not very effective in providing content about what to think, but the ability to influence our perceptions about what others think is high. Therefore, the media can naturally be interpreted as a source of spiral of silence. According to Tsfati and Cappella (2003), in the context of news media, individuals who do not trust the mainstream media are skeptical and prefer nonmainstream media sources such as the internet. Skeptical individuals are seeking diversity in media resources. Therefore, media skepticism is thought to may be effective in solving the alienation in the network society in the informal learning process.

\section{Method}

\subsection{Research Design}

The study is a quantitative research and modeled as correlational research. According to Weathington, Cunningham and Pittenger $(2010,299)$ "correlational research allows to study the relationship between two or more variables.

In the study, the alienation of the network society in informal learning was investigated within the context of "political, social, religious, cultural contents that the society is sensitive". University students aged 18-31 years included in the study are defined as young adults and have educational responsibilities within the scope of the subject (political, social, religious, cultural contents that the society is sensitive) expressed by their active citizenship responsibilities. Therefore, educational alienation related to the stated subject can not be accepted according to active citizenship approach. In the study, the evaluation of alienation was carried out through spiral of silence indicators and parameters. The participants' silence about "political, social, religious, cultural contents that the society is sensitive" was regarded as a sign of alienation. Therefore, as individuals can not use the opportunities of cognitive experience on Facebook, which is the informal learning environment related to the stated subject, they can not reach the feedbacks related to themselves and their environment, they can not operate the dialectical process and they enter into a process of alienation towards itself and its environment.

\subsection{Participant (Subject) Characteristics}

University students from ages 18 to 31 (young adults) are participating in the research. The criterion considered in setting the study group (participants) is that the participants were active Facebook users. Data were collected from 
477 participants with selected by purposeful sampling technique (university students - active Facebook users) and convenience sampling technique (Facebook users reached by researcher). Participant opinions with missing value in the data screening phase were excluded from analysis and evaluation and the number of participants decreased to 443 . 58.9 percent of the participants (261 subjects) are female and 41.1 percent (182 subjects) are male. When the participants' Facebook profiles are examined, the following table appears.

Table 1. Characteristic Analysis of Participants' Facebook Profiles

\begin{tabular}{|c|c|c|c|}
\hline & & $\mathrm{f}$ & $\%$ \\
\hline \multirow{2}{*}{$\begin{array}{l}\text { Do you use your personal / private ID } \\
\text { in your Facebook profile? }\end{array}$} & Yes & 429 & 96,8 \\
\hline & No & 14 & 3,2 \\
\hline \multirow{4}{*}{$\begin{array}{l}\text { How many friends do you have on } \\
\text { Facebook? }\end{array}$} & Between $0-150$ friends $*$ & 83 & 18,7 \\
\hline & Between 151-500 friends & 266 & 60,0 \\
\hline & Between 501-1000 friends & 78 & 17,6 \\
\hline & 1001 and over & 16 & 3,6 \\
\hline \multirow[b]{2}{*}{ Facebook Friend Profile } & Only Close Frieds & 100 & 22,6 \\
\hline & $\begin{array}{l}\text { Close Friends and others (from different } \\
\text { statuses as teacher, politician etc.) }\end{array}$ & 343 & 77,4 \\
\hline \multirow{2}{*}{$\begin{array}{l}\text { Do you add individuals to your } \\
\text { Facebook group who do not have the } \\
\text { same political, religious, cultural and } \\
\text { social point of view as yours? }\end{array}$} & Yes & 383 & 86,5 \\
\hline & No & 60 & 13,5 \\
\hline \multirow{7}{*}{$\begin{array}{l}\text { How many days a week do you use } \\
\text { Facebook? }\end{array}$} & 1 day a week & 7 & 1,6 \\
\hline & 2 days in a week & 20 & 4,5 \\
\hline & 3 days in a week & 15 & 3,4 \\
\hline & 4 days a week & 19 & 4,3 \\
\hline & 5 days a week & 25 & 5,6 \\
\hline & 6 days a week & 9 & 2,0 \\
\hline & Every day of the week & 348 & 78,6 \\
\hline \multirow{6}{*}{$\begin{array}{l}\text { How many hours a day do you use } \\
\text { Facebook? }\end{array}$} & Less than 1 hour on average & 72 & 16,3 \\
\hline & Average 1 hour & 124 & 28,0 \\
\hline & Average 2 hours & 115 & 26,0 \\
\hline & Average 3 hours & 69 & 15,6 \\
\hline & Average 4 hours & 32 & 7,2 \\
\hline & Average 5 hours & 31 & 7,0 \\
\hline
\end{tabular}

* Dunbar's Number (Dunbar, 2010): Users of social media such as Facebook can only maintain a meaningful relationship with approximately 150 people (social media friends).

\subsection{Data Collection Tool}

Data collection was done through the silence and media skepticism questionnaire developed by the researcher. Both instruments were validated by the opinions of expert academicians in media research and curriculum \& instruction fields.

For the silence questionnaire, silence codes were generated from the literature. And data were collected from the 10 items created within these codes. Participants can score between 0 and 10 according to their answers. The high score is indicative of the silence. The silence codes and criteria are presented in Annex 1.

The media skepticism questionnaire consists of two sub-dimensions. The level of "skepticism to others' posts" with 4 questions and the level of "skepticism to self-posts" with 2 questions are measured. The level of media skepticism rating is: 4 means very high level skepticism, 3 means high level skepticism, 2 means average level skepticism, 1 means low level skepticism, 0 means zero skepticism. Media skepticism items are presented in Annex 2. 


\subsection{Data Analysis Technique}

Mean, standard deviation, frequency and percent were used for the descriptive analyzes in the analyzes performed with the SPSS 21.0 program. Pearson correlation analysis was performed for the correlation analysis.

\section{Results}

The participants' levels of silence and media skepticism were described and the relationship between silence levels and media skepticism levels wasexamined. In this context, the analyzes carried out were presented.



Mean $(\bar{X}): 4,65$ s: 1,78

Graphic 1. Level of Silence (Alienation) of Participants

When the silence levels of the participants are examined, it is concluded that the group average is at the medium silence level. While only 4 participants do not engage in silence / alienate on Facebook usage, other participants show more or less silent / alienating behavior. When the participants' level of silence shown in Graphic 1 is examined, it is understood that there is a serious problem. Young adults who are university students are under the influence of others in their post and are considered to shape their behavior according to the reactions of others. This is a problem that should be considered. Young adults' silence about the "political, social, religious, cultural contents that the society is sensitive" means they are alienating to the network society they are a member of.

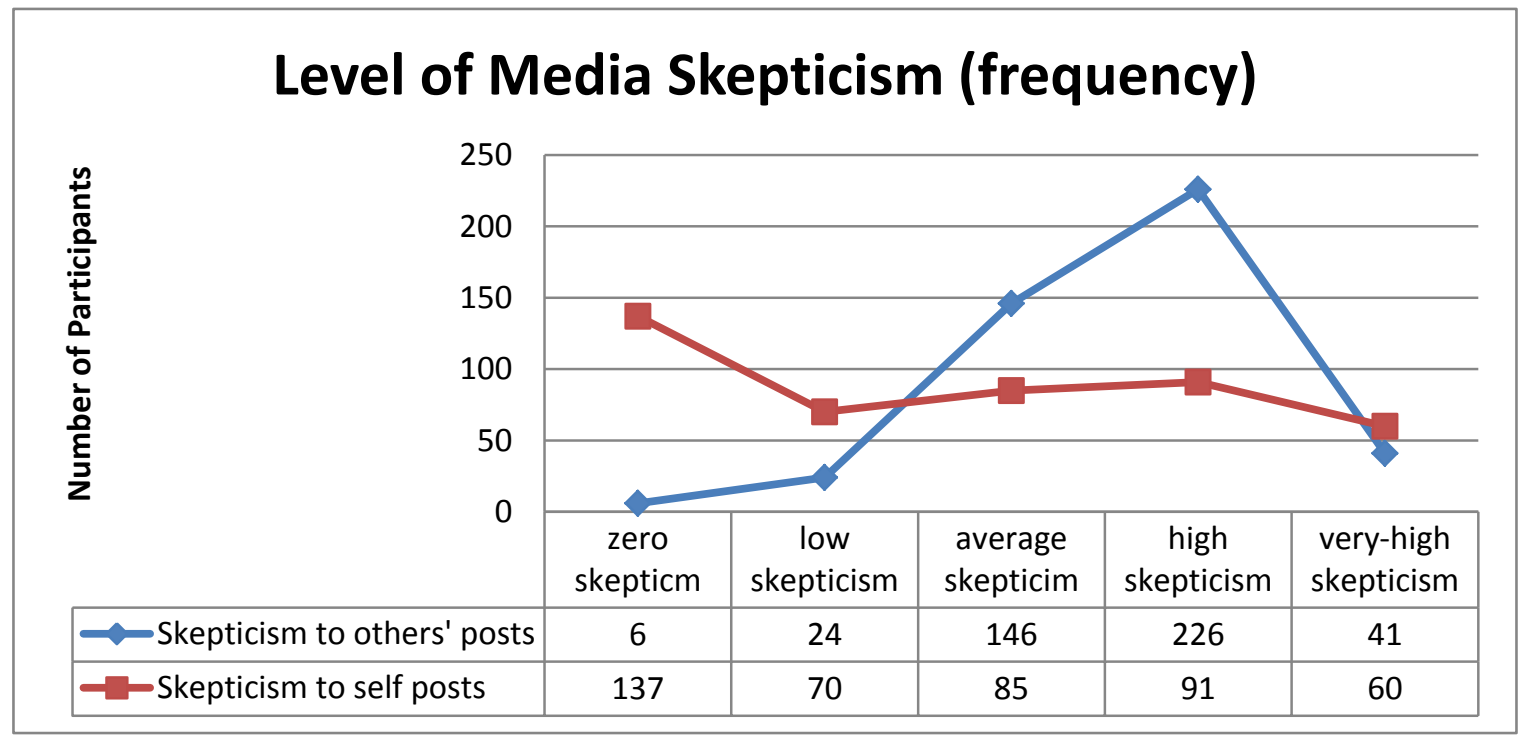

Graphic 2. Media Skepticism Levels of Participants

Skepticism to others' posts mean $(\bar{X}): 2.61 \mathrm{~s}: .78$

Skepticism to self posts mean $(\bar{X}): 1.70 \mathrm{~s}: 1.43$ 
When the level of media skepticism about the participants' posts about "political, social, religious, cultural contents, the society is sensitive" is examined, a remarkable result is encountered. Participants '"skepticism to others' posts" levels are higher than "skepticism to self posts". When the group means are examined, it is understood that "skepticism to others' posts" level is high skepticism level while "skepticism to self posts" level is low skepticism level. In addition, while there are 6 people who do not skeptic to the others' posts (zero skepticism), 137 people do not skeptic to the self posts. From this finding, it has been reached that the self-confidence of individuals is high and they do not take into account their mistakes. However, the high level of "skepticism to others' posts" is an indicator that individuals have a questioning, criticizing and evaluating character.

Table 2. Correlation between SoS and Media Skepticism (Pearson Correlation Analysis)

\begin{tabular}{llcc}
\hline & & Skepticism to others' posts & Skepticism to self posts \\
\hline \multirow{3}{*}{ SoS } & Pearson Correlation & $-.098^{*}$ & -.016 \\
\cline { 2 - 4 } & Sig. (2-tailed) & .039 & .734 \\
\cline { 2 - 4 } & $\mathrm{N}$ & 443 & 443 \\
\hline
\end{tabular}

*. Correlation is significant at the 0.05 level (2-tailed).

**. Correlation is significant at the 0.01 level (2-tailed).

When Table 2 is examined, there is a significant, negative and low level of correlation between SoS and "skepticism to others' posts" ( $\mathrm{r}=-.098 ; \mathrm{p}<0.01)$. As individuals' levels of "skepticism to others' posts' increase, there is a possibility that individuals' levels of silence / alienation may decrease. In the same case, the level of silence / alienation is likely to increase as the levels of "skepticism to others' posts" decrease.

There was no significant relationship between participants' SoS levels and skepticism to self-posts $(\mathrm{r}=-.016$; p> .05).

\section{Discussion}

In this research, where the question of whether or not the members of the network society are or are not active members of the community is questioned, different and remarkable results have been encountered. In the context of network society, Facebook has been evaluated as an informal learning opportunity and inquiries have been made on the basis of the learning theme of "political, social, religious, cultural contents that the society is sensitive". In the networking society, considered as an informal learning environment (on Facebook), the Spiral of Silence indicators were considered as a reference to alienation and the participants' silence levels on Facebook were examined. It has been investigated whether there is a potential for media skepticism to solve the problem of silence, ie alienation.

As Facebook users, it is understood that young adults' level of "spiral of silence" about "political, social, religious, cultural contents that the society is sensitive" is medium level. Only 4 participants are out of spiral of silence. 439 participants are in "spiral of silence" at different levels. This is an indicator that young adults, who are expected to exhibit active citizenship characteristics, are alienating to "political, social, religious, cultural contents that society is sensitive" on Facebook. Participants who are university students are assumed to have a certain level of intellectual competence and strong social responsibilities. Therefore, although there are participants with low levels of alienation, it is necessary to consider the result seriously. When the literature is examined, different causes are reached to explain this effect. With regard to Greenfield (2009), participants may be in the media diet. But it is thought to be a low possibility because ecause the level of Facebook usage is high. When consider the perspectives of Madge, Meek, Wellens and Hooley (2008), who consider Facebook as a social glue, it is understood that the "cooperation and solidarity" which is effective in solving learning difficulties are not transferred into practice on the learning themes which about "political, social, religious, cultural contents that society is sensitive". Likewise, the "social interaction" that Ringer and Briziarelli (2016) emphasize can not prevent alienation. In fact, the reason for this problem is likely to be a human condition, as Kellner (2006) points out. It is thought that the threat of exclusion, the social isolation anxiety, and the lack of a strong climate of opinion are the direct determinants of alienation (Noelle-Neumann, 1974; 1977; 1991). The researches of Gearhart and Zhang (2015), Hoffman and Lutz (2017), Miyata, Yamamoto, and Ogawa (2015) and $\mathrm{Wu}$ (2017) also support this justification. At this point, the transformation of the "spiral of dialogue", which is naturally occurring in Facebook, to the silence of young adults is a matter of concern.

The media skepticism levels of young adults are remarkable. While at a high level of skepticism to posts of others about "political, social, religious, cultural contents that society is sensitive", they are at a low level of skepticism about their own posts. In addition, while there are 6 participants who do not skeptic (zero skepticism) to posts of others, 137 participants do not skeptic to their own posts. This is an indication of the young adults approaching other people's posts with a questioning, critical, septic character. This is among the features of 21 st-century citizens and 
learners. However, the fact that young adults do not approach the same way to their own posts is a situation that needs to be investigated. When the relationship between media skepticism levels and spiral of silence is examined; There is a significant, negative, low level of relationship between being skeptic to the others' posts about "political, social, religious, cultural contents that society is sensitive" and spiral of silence. There is no significant relationship between the levels of skepticism and spiral of silence on the self-posts of young adults. In other words, the level of alienation (for the "political, social, religious, cultural contents that society is sensitive") of individuals on Facebook and their level of skepticism to the others' posts are two variables that have the potential to effect each other.

As a result, in the second decade of the 2000s, within the opportunities offered by information technology, the network society has emerged as a strong educational opportunity. But in order to benefit from this opportunity, the alienation of users to the network society and the network culture must be prevented. Media skepticism towards the others' posts at the network society has the potential to be an effective parameter to prevent alienation. In this context, it is suggested that users should develop media skepticism towards the others' posts.

\subsection{Limitations}

This study has some limitations. Research has been conducted only on Facebook. Other network society applications have not been included in the research. In addition, university students from the age of 18-31 have joined the research as members of the network society. Therefore the results of the study can not generalized for other individuals with different age groups. Participants' alienation and media skepticism levels were examined through their own expressions (self-assessments); no further observations have been made by the researcher.

\section{References}

Åkerlind, G. S. \& Trevitt, A. C. (1999). Enhancing self-directed learning through educational technology: When students resist the change. Innovations in Education and Training International, 36(2), 96-105. https://doi.org/10.1080/1355800990360202

Albors, J., Ramos, J.C. \& Hervas, J.L. (2008). New learning network paradigms: Communities of objectives, crowdsourcing, wikis and open source. International Journal of Information Management, 28, 194-202. https://doi.org/10.1016/j.ijinfomgt.2007.09.006

Andrejevic, M. (2014). Alienation's return. In C. Fuchs and M. Sandoval (Eds.), Critique, social media and the information society (pp. 179-190). New York, NY: Routledge.

Bessenyei, I. (2008). Learning and teaching in the information society. Elearning 2.0 and connectivism. Revista de Informatica Sociala, 5(9), 4-14.

Bull, G., Thompson, A., Searson, M., Garofalo, J., Park, J., Young, C., \& Lee, J. (2008). Connecting informal and formal learning: Experiences in the age of participatory media. Contemporary Issues in Technology and Teacher Education, 8(2), 100-107.

Cain, J. \& Policastri, A. (2011). Instructional design and assessment. Using Facebook as an Informal Learning Environment. American Journal of Pharmaceutical Education, 75(10), 1-8. https://doi.org/10.5688/ajpe7510207

Castells, M. (2000). Toward a sociology of the network society. Contemporary Sociology, 29(5), 693-699. https://doi.org/10.2307/2655234

Castells, M. (2004). The network society: a cross-cultural perspective. Edward Elgar Publishing, Inc.: USA. https://doi.org/10.4337/9781845421663

Castells, M. (2010). The Rise of the Network Society ( $2^{\text {nd }}$ ed.). John Wiley \& Sons Ltd: UK.

Chan, T-W., Hue, C-W., Chou, C-Y. \& Tzeng, O.J.L. (2001). Four spaces of network learning models. Computers \& Education, 37, 141-161. https://doi.org/10.1016/S0360-1315(01)00044-6

Chang, B., Cheng, N-H., Deng, Y-C. and Chan, T-W. (2007). Environmental design for a structured network learning society. Computers \& Education, 48, 234-249. https://doi.org/10.1016/j.compedu.2004.11.008

Chen, K. (2011). A test of the spiral of silence theory on young adults' use of social networking sites for political purposes. Graduate Theses and Dissertations. Iowa State University.

Chen, B. \& Bryer, T. (2012). Investigating instructional strategies for using social media in formal and informal learning. IRRODL The International Review of Research and Distributed Learning, 13(1). https://doi.org/10.19173/irrodl.v13i1.1027

Chris, J. (2004) Networks and learning: communities, practices and the metaphor of networks, ALT-J Research in Learning Technology, 12(1), 81-93. https://doi.org/10.1080/0968776042000211548 
Colardyn, D. \& Bjornavold, J. (2004). Validation of formal, non-formal and informal learning: Policy and practices in EU Member States. European Journal of Education, 39(1), 69-89. https://doi.org/10.1111/j.0141-8211.2004.00167.x

Dean, D. G. (1961). Alienation: Its meaning and measurement. American Sociological Review, 26(4), 753-758. https://doi.org/10.2307/2090204

Dunbar, R. (2010). How many friends does one person need? Dunbar's number and other evolutionary quirks. Massachusetts: Harvard University Press.

Ellison, N.B., Steinfield, C. \& Lampe, C. (2007). The Benefits of facebook "friends:" Social capital and college students' use of online social network sites. Journal of Computer-Mediated Communication, 12(4), 1143-1168. https://doi.org/10.1111/j.1083-6101.2007.00367.x

Erjavec, K. (2013). Informal learning through Facebook among Slovenian pupils. Comunicar, 41(XXI), 117-126. https://doi.org/10.3916/C41-2013-11

Eshach, H. (2007). Bridging in-school and out-of-school learning: Formal, non-formal, and informal education. Journal of Science Education and Technology, 16(2), 171-190. https://doi.org/10.1007/s10956-006-9027-1

Foz, J. \& Warber, K. M. (2015). Queer identity management and political self-expression on social networking sites: A co-cultural approach to the spiral of silence. Journal of Communication, 65, 79-100. https://doi.org/10.1111/jcom.12137

Gearhart, S. \& Zhang, W. (2015). "Was it something i said?" "No, it was something you posted!" A study of the spiral of silence theory in social media contexts. Cyberpsychology, Behavior, and Social Networking, 18(4), 208-2013. https://doi.org/10.1089/cyber.2014.0443

Greenfield, P. M. (2009). Technology and informal education: What is taught, what is learned. Science, 323, 69-71. https://doi.org/10.1126/science. 1167190

Greenhow, C. \& Lewin, C. (2016) Social media and education: Reconceptualizing the boundaries of formal and informal learning. Learning, Media and Technology, 41(1), 6-30. https://doi.org/10.1080/17439884.2015.1064954

Hayes, A. F. (2007). Exploring the forms of self-censorship: On the spiral of silence and the use of opinion expression avoidance strategies. Journal of Communication 57, 785-802. https://doi.org/10.1111/j.1460-2466.2007.00368.x

Hayes, A. F., Matthes, J., \& Eveland, W. P. (2011). Stimulating the quasi-statistical organ: Fear of social isolation motivates the quest for knowledge of the opinion climate. Communication Research, 40, 439-462. https://doi.org/10.1177/0093650211428608

Haythornthwaite, C. \& Laat, M. (2010). Social networks and learning networks: Using social network perspectives to understand social Learning. 7th International Conference on Networked Learning.

Hew, K. F. (2011). Students' and teachers' use of Facebook. Computers in Human Behavior, 27(2), 662-676. https://doi.org/10.1016/j.chb.2010.11.020

Hoffman, C.P. \& Lutz, C. (2017). Spiral of Silence 2.0: Political Self-Censorship among Young Facebook Users. SMSociety'17, July 28-30, 2017, Toronto. https://doi.org/10.1145/3097286.3097296

Kellner, D. (2006). New technologies and alienation: Some critical reflections. Dans L. Langman \& D. Kalekin-Fishman (dir.), The evolution of alienation: Trauma, promise, and the millennium (p.47-68). Maryland: Rowman and Littlefield.

Krumsvik, R. (2009). Situated learning in the network society and the digitised school. European Journal of Teacher Education, 32(2), 167-185. https://doi.org/10.1080/02619760802457224

Kryshtaleva, M.K. (2016). The processes of alienation in the modern world and their features in visual culture. AI \& Soc, 32,117-120. https://doi.org/10.1007/s00146-016-0657-4

La Belle, T.J. (1982). Formal, nonformal and informal education: A holistic perspective on lifelong learning. International Review of Education, 28(2), 159-175. https://doi.org/10.1007/BF00598444

Lai,K.W., Khaddage, F. \& Knezek, G. (2013). Blending student technology experiences in formal and informal learning. Journal of Computer Assisted Learning, 29, 414-425. https://doi.org/10.1111/jcal.12030

Laurillard, D. (2009). The pedagogical challenges to collaborative technologies. International Journal of Computer Supported Collaborative Learning, 4(1), 5-20. https://doi.org/10.1007/s11412-008-9056-2 
Leshchenko, T., Sokolova, I. \&Teplova, L. (2016). The inevitability of the alienation of communication in the era of globalisation. 16th International Scientific Conference on Economic and Social Development - The Legal Challenges of Modern World - Split, 1-2 September 2016, 753-761.

Madge, C., Meek, J., Wellens, J. \& Hooley, T. (2008). Facebook, social integration and informal learning at university. Learning, Media and Technology, 34(2), 141-155. https://doi.org/10.1080/17439880902923606

Mau, R. Y. (1992). The validity and devolution of a concept: Student alienation. Adolescence, 27(107), 731-741.

McLuhan, M. \& Powers, B.R. (1989). The global village: Transformations in world life and media in the 21st century. USA: Oxford University Press

Miyata, K., Yamamoto, H. and Ogawa, Y. (2015). What affects the spiral of silence and the hard core on Twitter? An analysis of the nuclear power issue in Japan. American Behavioral Scientist, 59(9) 1129-1141. https://doi.org/10.1177/0002764215580618

Mix, K. K. (2010). Online social networking: Exploring the relationship between use of Web-based social technologies and community college student engagement. ProQuest, UMI Dissertations Publishing

Nasr, M. \& Ouf, S. (2011). An ecosystem in e-learning using cloud computing as platform and Web2.0. The Research Bulletin of Jordan, 2(4), 134-140.

Noelle-Neumann, E. (1974). The spiral of silence: A theory of public opinion. The Journal of Communication, 24(2), 43-51. https://doi.org/10.1111/j.1460-2466.1974.tb00367.x

Noelle-Neumann, E. (1977). Turbulences in the climate of opinion: Methodological applications of the spiral of silence theory. The Public Opinion Quarterly, 41(2), 143-158. https://doi.org/10.1086/268371

Noelle-Neumann, E. (1991). The theory of public opinion: The concept of the spiral of silence. In J. A. Anderson (Ed.), Communication yearbook/14 (pp. 256-308). Thousand Oaks, CA, US: Sage Publications, Inc. https://doi.org/10.1080/23808985.1991.11678790

O'Keeffe, G.S., \& Clarke-Pearson, K.(2011). The impact of social media on children, adolescents, and families. PEDIATRICS, 127(4), 800-804. https://doi.org/10.1542/peds.2011-0054

Pettenati, M.C. \& Ranieri, M. (2006). Informal learning theories and tools to support knowledge management in distributed CoPs. E. Tomadaki and P. Scott (Eds.): Innovative approaches for learning and knowledge sharing, EC-TEL 2006 Workshops Proceedings, ISSN 1613-0073, p. 345-355, 2006.

Ringer, A.L. \& Briziarelli, M. (2016). The ambivalent spectacle: A critical inquiry on web 2.0 media and alienation. New Proposals: Journal of Marxism and Interdisciplinary Inquiry, 9(1), 38-48.

Snyder, I. (2001). A new communication order: Researching literacy practices in the network society. Language and Education, 15(2\&3), 117-131. https://doi.org/10.1080/09500780108666805

Tsfati, Y. (2003). Media scepticism and climate of opinion perception. International Journal of Public Opinion Research, 15(1), 65-82. https://doi.org/10.1093/ijpor/15.1.65

Tsfati, Y. \& Cappella, J.N. (2003). Do people watch what they do not trust? Exploring the association between news media skepticism and exposure. Communication Research, 30(5), 504-529. https://doi.org/10.1177/0093650203253371

van Dijk, J.A.G.M. (2006). The network society social aspects of new media (2 ${ }^{\text {nd }}$ ed.). SAGE Publications Ltd.

Vivian, R. (2011). University students' informal learning practices using Facebook: Help or hindrance? Communications in Computer and Information Science Conference. R. Kwan et al. (Eds.): ICT 2011, CCIS 177, pp. 254-267

Warschauer, M. (2007). The paradoxical future of digital learning. Learn Inq, 1, 41-49. https://doi.org/10.1007/s11519-007-0001-5

Weathington, B.L., Cunningham, C.J.L. \& Pittenger, D.J. (2010). Research methods for the behavioral and social sciences. USA: John Wiley \& Sons, Inc.

Weinstein, C. \& Mayer, R. (1983). The teaching of learning strategies. Innovation Abstracts, 5(32), 4, http://eric.ed.gov/PDFS/ED237180.pdf

$\mathrm{Wu}$, T.Y. (2017). Exploring the predictors of the spiral of silence in online news discussions. Doctoral Dissertations. 1396. University of Connecticut Graduate School. http://digitalcommons.uconn.edu/dissertations/1396 
Annex 1. Silence Questionnaire Code, Items and Criterion Table

\begin{tabular}{|c|c|c|c|}
\hline No & Code & Items & Criterion \\
\hline 1 & & $\begin{array}{l}\text { In your Facebook account, do you block friends so that they do not } \\
\text { follow your posts and shares? }\end{array}$ & $\begin{array}{l}\text { Yes: in SoS } \\
\text { No: out of SoS }\end{array}$ \\
\hline 2 & & $\begin{array}{l}\text { Is it important for you to your Facebook friends make comments to your } \\
\text { posts and shares about "political, social, religious, cultural contents that } \\
\text { society is sensitive" in your Facebook account? }\end{array}$ & $\begin{array}{l}\text { Yes: out of SoS } \\
\text { No: in SoS } \\
\text { No share: in SoS }\end{array}$ \\
\hline 3 & .气̊ี & $\begin{array}{l}\text { When you post "political, social, religious, cultural contents that society } \\
\text { is sensitive" on your Facebook account, do you get negative answers } \\
\text { from your Facebook friends? }\end{array}$ & $\begin{array}{l}\text { Yes: out of SoS } \\
\text { No: in SoS } \\
\text { No share: in SoS }\end{array}$ \\
\hline 4 & 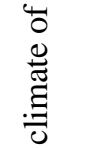 & $\begin{array}{l}\text { When you post "political, social, religious, cultural contents that society } \\
\text { is sensitive" on your Facebook account, are you anxious about negative } \\
\text { comments to your posts by Facebook friends? }\end{array}$ & $\begin{array}{l}\text { Yes: in SoS } \\
\text { No: out of SoS }\end{array}$ \\
\hline 5 & 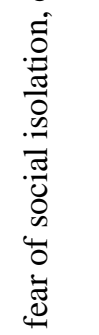 & $\begin{array}{l}\text { If you have a friend in your Facebook friends group who you think have } \\
\text { a different political, religious, cultural or social point of view, what do } \\
\text { you do in the following? } \\
\text { ( a ) I do not disclose my views on Facebook. I use Facebook just for } \\
\text { fun. } \\
\text { ( b ) I try to share the opposite of their ideas, which can influence their } \\
\text { ideas. }\end{array}$ & $\begin{array}{l}\text { a: in } \operatorname{SoS} \\
\text { b: out of SoS }\end{array}$ \\
\hline 6 & 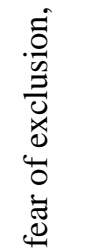 & $\begin{array}{l}\text { If you have a friend in your Facebook friends group who you think have } \\
\text { a same political, religious, cultural or social point of view, what do you } \\
\text { do in the following? } \\
\text { (a) I do not disclose my views on Facebook. I use Facebook just for fun. } \\
\text { (b ) I try to share posts that similar to their ideas. }\end{array}$ & $\begin{array}{l}\text { a: in } \operatorname{SoS} \\
\text { b: out of SoS }\end{array}$ \\
\hline 7 & 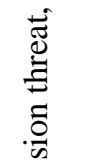 & $\begin{array}{l}\text { If you have a discussion on Facebook on "political, social, religious, } \\
\text { cultural contents that society is sensitive" and your views are different } \\
\text { from the discussion group, will you participate and present your ideas? }\end{array}$ & $\begin{array}{l}\text { Yes: out of SoS } \\
\text { No: in SoS } \\
\text { No share: in SoS }\end{array}$ \\
\hline 8 & 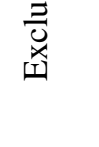 & $\begin{array}{l}\text { In your Facebook account, do you feel more free than your real life about } \\
\text { expressing your opinions about "political, social, religious, cultural } \\
\text { contents that society is sensitive"? }\end{array}$ & $\begin{array}{l}\text { Yes: out of SoS } \\
\text { No: in SoS }\end{array}$ \\
\hline 9 & & $\begin{array}{l}\text { Have you deleted or re-edited any content in your Facebook account that } \\
\text { you have shared because of your group of friends? }\end{array}$ & $\begin{array}{l}\text { Yes: in SoS } \\
\text { No: out of SoS }\end{array}$ \\
\hline 10 & & $\begin{array}{l}\text { Does Facebook have a power over your decisions and cause you to } \\
\text { regulate your profile like how others want to see it? }\end{array}$ & $\begin{array}{l}\text { Yes: in SoS } \\
\text { No: out of SoS }\end{array}$ \\
\hline
\end{tabular}


Annex 2. Media Skepticism Questionnaire Items

Skepticism to I am skeptical about the fact that the posts that include "political, social, religious, cultural others' posts contents that society is sensitive" on Facebook is real or fiction.

I am skeptical about whether Facebook's "political, social, religious, cultural contents that society is sensitive" reflects the current issue.

I am skeptical about whether posts on Facebook about "political, social, religious, cultural contents, society is sensitive" includes prejudice.

I am skeptical about whether posts on Facebook about "political, social, religious, cultural contents, society is sensitive" are intended to manipulate me.

Skepticism to self I am skeptical about whether or not I am misrepresenting any aspect of "political, social, posts $\quad$ religious, cultural contents that society is sensitive" that I share in my own Facebook account.

I am skeptical whether I manipulate others related to "political, social, religious, cultural contents that society is sensitive" that I share in my own Facebook account. 